\title{
O meio, a mensagem e suas origens: um estudo acerca do processo criativo divulgado no blog de Adam Curtis
}

Rafael Ghiraldelli da Silva ${ }^{1}$

\section{Introdução}

ADAM CURTIS (1955- ) É UM CINEASTA BRITÂNICO INTERESSADO EM INVESTIGAR RELAÇÕES HISTÓRICAS ENTRE SOCIEDADE, política e tecnologia por via do documentário. Desde fins dos anos 1980, Curtis trabalha quase que exclusivamente para os canais de televisão da British Broadcasting Corporation (BBC) realizando minisséries e longas-metragens que se aprofundam nas possíveis convergências - e nas consequências da interação - entre tecnologias e epistemologias oriundas de uma ou mais potências capitalistas, bem como nos tipos de colonialidade que elas permitiram exercer sobre os povos do chamado Sul global. Em suma, Curtis se preocupa com as maneiras pelas quais o discurso político embutido em artefatos ${ }^{2}$ que atuam como mediadores na relação entre humanidade e o mundo ao seu redor também molda determinados ideais de progresso, de afeto, de desenvolvimento econômico e de liberdade.

Um exemplo disso pode ser visto na série The Trap: What Happened to Our Dream of Freedom ( $A$ Armadilha: O que Aconteceu com Nosso Sonho de Liberdade), de 2007. Nela, Curtis traça uma associação entre o desenvolvimento da teoria dos jogos e da cibernética nos Estados Unidos do começo da Guerra Fria e um processo de compreensão ocidental das relações interpessoais progressivamente racionalizadas. É a partir dos anos 1950 que Curtis identifica figuras tais quais o matemático John Forbes Nash Jr. (1928-2015) e o psicólogo R. D. Laing (1927-1989) como membros da comunidade científica global cada vez mais convictos de que a estrutura social moderna é uma trama que se auto-organiza a partir do pressuposto íntimo de que cada pessoa conspira contra outras o tempo todo. Logo, as ações de uma dada pessoa são reguladas segundo aquilo que ela acha que outras pessoas poderão fazer para levar vantagem em cima dela. A liberdade individual, entendida aqui como o direito de se fazer o que bem se entende, é administrada/interditada/cerceada por uma forma dominadora de liberdade coletiva - ou, mais precisamente, de liberalismo autorregulador da sociedade. Essa é uma perspectiva que se reflete também, segundo Curtis, em pesquisas feitas no campo da genética - com as teorias do britânico Richard Dawkins (1941 - ) sobre o gene egoísta - e a antropologia.

No caso desse último campo do saber, Curtis destaca o filme The Ax Fight (A Luta de Machado), dirigido por Napoleon Chagnon e Tim Asch em 1975. Trata-se de um registro de uma luta supostamente genuína e espontânea entre duas tribos yanomami sobre o qual Chagnon e Asch se debruçam, analisando quadro a quadro. Concluem, a partir de um entendimento genocêntrico da situação, que indígenas mais geneticamente próximos se colocaram em defesa um do outro perante seus parentes geneticamente distantes. Curtis chega a entrevistar Chagnon no segundo episódio de The Trap, perguntando ao antropólogo se, na verdade, não era a presença de uma equipe de filmagens como a dele - que trouxe "presentes" aos yanomami tais como os machados referidos no

\footnotetext{
${ }^{1}$ Mestrando do Programa de Pós graduação em Artes Visuais vinculado à linha de pesquisa em Poéticas Visuais e Processos Criativos do Instituto de Artes da Universidade Estadual de Campinas (PPGAV/IA/Unicamp). Contato: ghiralds@gmail.com

${ }^{2}$ WINNER, Langdon. The Whale and the Reactor: a search for limits in an age of high technology. Chicago: The University of Chicago Press, 1986. p. 19.
} 
título do filme - que provocou o conflito em primeiro lugar. Chagnon se mostra claramente incomodado com esse questionamento e abandona a entrevista.

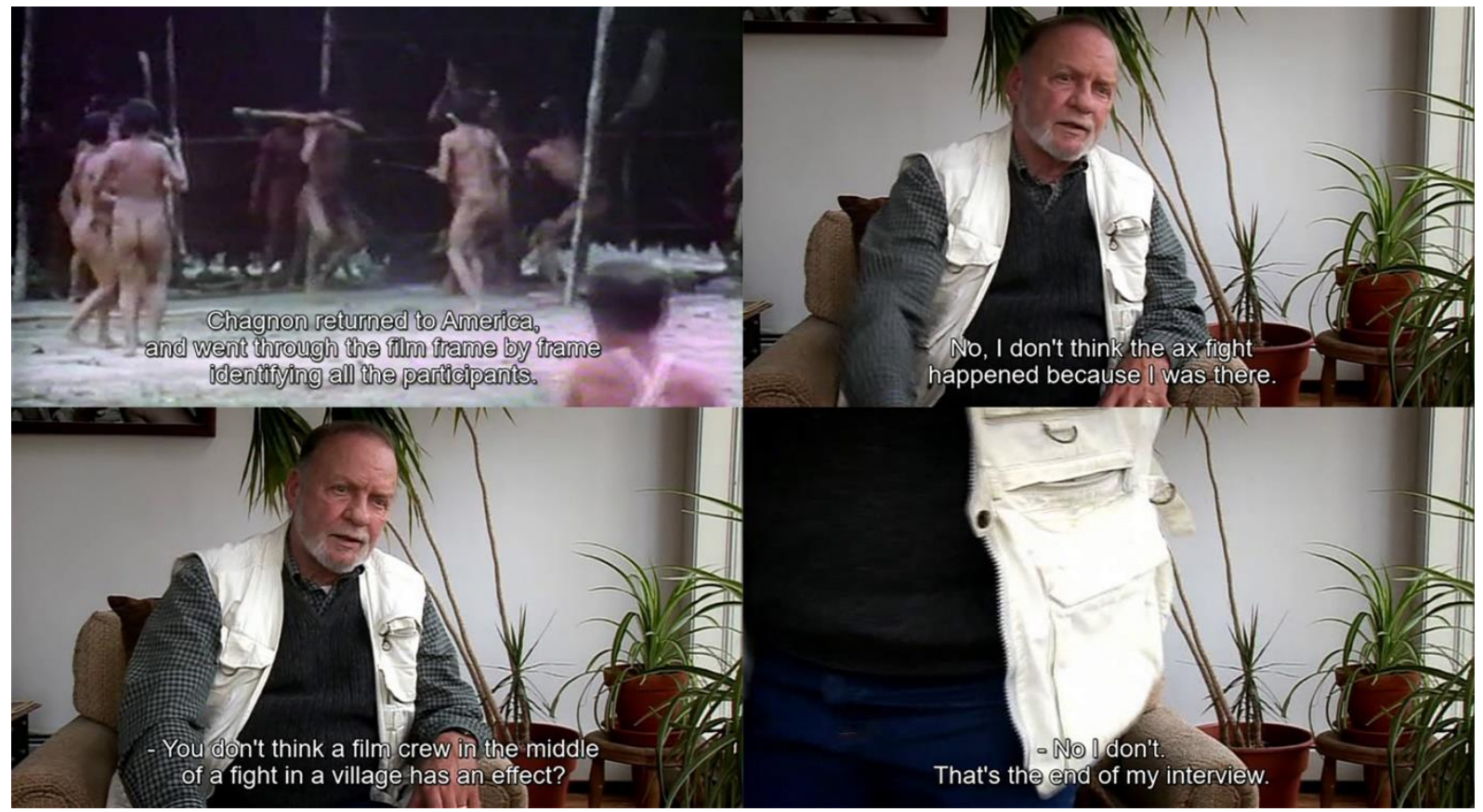

Figura 1: Sequência de fotogramas em que o antropólogo Napoleon Chagnon é entrevistado por Curtis a respeito do filme The Ax Fight. Fonte: CURTIS, Adam (dir.). The Trap: What Happened to Our Dream of Freedom? [Minissérie para TV]. Reino Unido: British Broadcasting Corporation, 2007.

Como se vê, Curtis se vale de um dispositivo do cinema documentário bastante reconhecido e consolidado - as entrevistas registradas em película ou em vídeo na forma estética de cabeças falantes - para delinear sua argumentação contra modelos de interpretação sistêmicos e ultra-racionalizados da sociedade ocidental para consigo mesma ou para com culturas consideradas exóticas ou primitivas. Contudo, o ápice da construção retórica de Curtis em The Trap se dá em um momento de subversão do dispositivo - ou seja, na decisão de manter o registro do abandono da entrevista por Chagnon no corte final dos episódios da série. Curtis se torna ciente do papel que a montagem cinematográfica tem para articular conceitos por si só, e passa a usá-la cada vez mais como marca de sua autoria.

Demonstrações como aquelas feitas pelo conhecido Efeito Kuleshov evidenciam a psicodinâmica inerente à compreensão de imagens que se sucedem temporalmente. O significado que nós, espectadores, atribuímos ao rosto de uma pessoa capturado pela câmera é influenciado pelo que aparece imediatamente antes e pelo que aparece em seguida. Tomando o referido efeito como exemplo: se o rosto de um personagem é visto em um dado plano em close-up, olhando para algo no fora-de-campo com uma expressão neutra sucedida por um corte para outro plano que focaliza um prato de sopa, tendemos a interpretar que esse mesmo personagem sente fome. E é justamente a montagem cinematográfica que possibilita isso, uma vez que implica em um processo planejado de seleção de imagens que, ao serem justapostas, oferecem possibilidades de interpretação que vão ao encontro da visão de mundo de um determinado cineasta. A fruição de um peça audiovisual qualquer é influenciada pelo modo que os cortes conectam diferentes tempos e lugares em favor de uma coerência espaço-temporal forjada, que leva o espectador a uma suspensão temporária da descrença para com as situações representadas. Outros tempos e lugares se tornam possíveis, tanto no âmbito da ficção quanto no do documentário. 
A montagem não deixa de ser essencial também para transmitir verdades pessoais que podemos tanto adotar como nossas quanto recusar totalmente. Em documentários como The Ax Fight, a montagem articula imagens com o intuito de reforçar alguma tese defendida pelos diretores. No caso: a de que genes influenciam diretamente as formas pelas quais os yanomami se relacionam com seus pares. Autoridades do saber são ocasionalmente convidadas a realizar depoimentos que corroboram a visão do diretor perante a câmera. Mas em documentários como aqueles dirigidos por Curtis após a realização de The Trap, percebe-se outra abordagem. Há uma progressiva supressão das entrevistas feitas com especialistas em prol de uma atualização das estratégias de montagem através da estética do banco de dados ${ }^{3}$ e do emprego de técnicas digitais de pós-produção para edição de material audiovisual ${ }^{4}$. Em outras palavras, Curtis passa a elaborar seu discurso se valendo quase que somente de imagens de arquivo cujos sentidos originais e eventuais ressignificações são costuradas entre si por meio de uma voz do saber ${ }^{5}$ megaenunciadora e inquestionável: a da narração em voice-over feita pelo próprio Curtis, que apresenta fatos históricos, opiniões e interpretações pessoais a partir daquilo que o espectador vê na tela de seu aparelho de TV.

Para entender como se deu essa transição de modos retóricos empregados por Curtis, vale analisar excertos de seu processo criativo, publicados desde 2009 em seu blog oficial, intitulado The Medium and The Message (O Meio e a Mensagem) em referência à célebre expressão do teórico da comunicação canadense Marshall McLuhan (1911-1980) incluída em seu livro Os meios de comunicação como extensões do homem: o meio é a mensagem $^{6}$. Fica subentendido na atualização da frase proposta por Curtis que o meio de comunicação na contemporaneidade não pode ser mais categorizado de acordo com o tipo de mensagem que veicula, mas como algo que complementa a mensagem no intuito de contextualizá-la e/ou ressignificá-la segundo os desejos do comunicador. O meio e a mensagem atualizam um ao outro, reciprocamente. Trata-se novamente de entender aí que há política embutida nos artefatos ${ }^{7}$.

Contudo, por mais que pareça simples constatar a validade do ponto de vista de Curtis, veremos adiante que nem mesmo ele consegue escapar da real complexidade compreendida na afirmação de McLuhan - a qual se mantém relevante como nunca em nossos tempos.

\section{O Meio e a Mensagem: o blog e as postagens de Curtis sobre projetos de autoria própria}

O referido blog encontra-se hospedado desde sua criação sob um domínio gerido pela BBC: $<$ https://www.bbc.co.uk/blogs/adamcurtis>. No texto de apresentação acessível logo na página inicial, o blog é identificado por Curtis como um website no qual ele expressa visões de mundo a partir de uma seleção de observações, histórias que gosta, ideias que acha fascinante, trabalhos em andamento (work in progress) e material obtido dos arquivos de imagens e sons da BBC.

O período de maior atividade do blog se deu entre 2009 e 2012. Trata-se de um intervalo de tempo que compreende, primeiramente, o lançamento de um filme experimental realizado por Curtis em parceria com a companhia de teatro britânica Punchdrunk (It Felt Like a Kiss), para, logo em seguida, apresentar aspectos de uma longa pesquisa que o cineasta iniciou com o intuito de expandir conceitos inicialmente discutidos na série The Trap.

Se é nessa série documental de 2007 que Curtis volta sua atenção às tentativas de imposição de formas viciadas de liberdade coletiva por meio da introjeção de técnicas e saberes dominantes, oriundos da

\footnotetext{
${ }^{3}$ ManOVICH, Lev. The language of new media. Cambridge: MIT Press, 2001, p. 218.

${ }^{4}$ Bourriaud, Nicolas. Pós-produção: como a arte reprograma o mundo contemporâneo. São Paulo: Martins Fontes, 2009.

${ }^{5}$ NiCHOLS, op. cit., p. 41-44.

${ }^{6}$ MCluhan, Marshall. Os meios de comunicação como extensões do homem. 6. ed. São Paulo: Cultrix, 1988. Grifos nossos.

${ }^{7}$ WINNER, op. cit., p. 19.
} 
epistemologia de um dado colonizador, e que permitem computar e comoditizar relações sociais diversas, é de 2009 em diante que Curtis direciona seu foco de análise para outras duas regiões distintas do mundo, mas sujeitas a processos de colonização que provocaram rupturas sociais afins: o Afeganistão e o antigo Congo Belga (atual República Democrática do Congo).

A partir de setembro de 2009, Curtis inicia uma série de postagens em que apresenta a extraordinária história de relacionamento do Ocidente com o Afeganistão nos últimos 200 anos. Intituladas Kabul: city number one (Kabul: cidade número $u m)^{8}$, tais postagens alternam pesquisas feitas pelo cineasta em referências bibliográficas diversas com conteúdo audiovisual ao qual ele teve acesso nos arquivos da BBC. Segundo texto publicado no blog por Curtis em julho de 2010, tal conteúdo compreende tudo o que a BBC acumulou sobre o Afeganistão em 30 anos, ocupando o tamanho aproximado de 18 terabytes (18 mil gigabytes) de armazenamento em disco rígido. Dada a precariedade de muitos desses registros antigos e da baixa resolução, possivelmente empregada em sua conversão do analógico para o digital (antes de 2010), pode-se dizer que representam um número expressivo de arquivos em formatos variados. Fotografias, vídeos, sons, entre outros tipos de documento foram compilados e estudados detidamente por Curtis. Uma parcela muito pequena deles serviu tanto para ilustrar as postagens do blog como se pôs na condição de evidência do que foi o Afeganistão antes da chegada de projetos ambiciosos de modernização/ocidentalização do país capitaneados por empreiteiras estadunidenses dos anos 1950 aos 1970. Comenta-se também sobre as incursões militares fracassadas do Reino Unido em fins do século 19 e sobre a complexidade étnica e cultural que atuou contra os interesses colonialistas britânicos na região.

Curtis identifica nessa diversidade algumas rivalidades históricas que seriam exploradas e intensificadas mais tarde por figuras que ambicionaram tomar o poder e unificar o Afeganistão sem levar em conta as múltiplas demandas de diferentes comunidades locais.

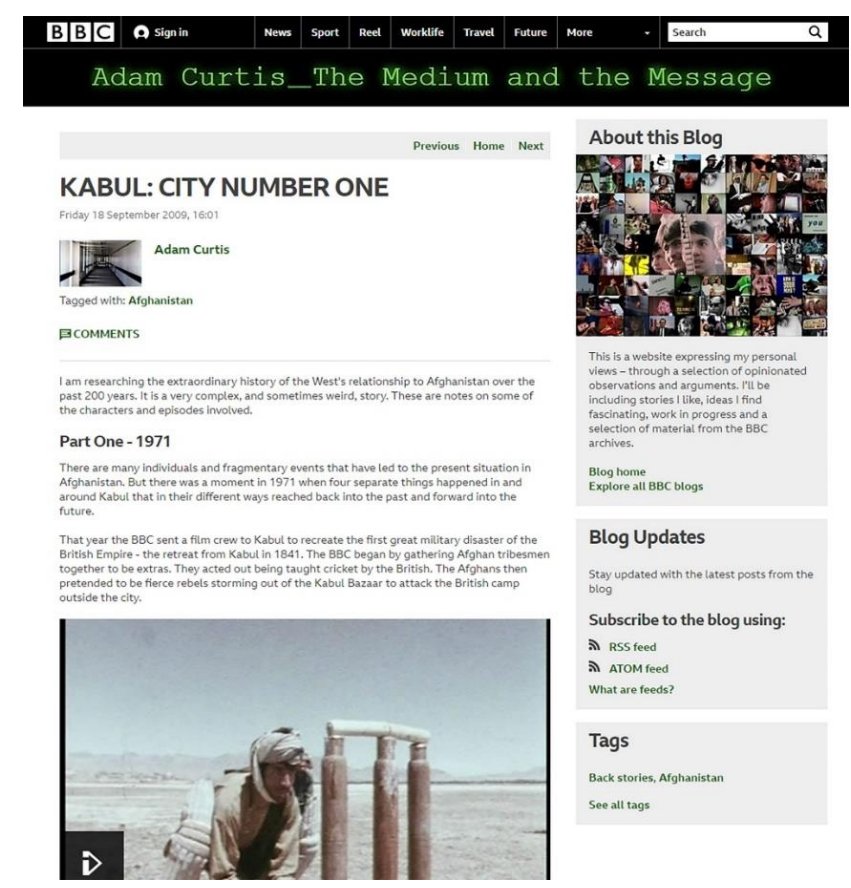

Figura 2: Captura de tela que mostra parte da primeira postagem (de dez) feitas sobre o Afeganistão no blog de Curtis. Fonte: CURTIS, Adam. The Medium and the Message. Disponível em: <https://www.bbc.co.uk/blogs/ adamcurtis/entries/fc69b85a-c6b1-3363-baeb-24418e99b683>. Acesso em: 03 jul. 2020.

\footnotetext{
${ }^{8}$ Kabul (ou Cabul) é a atual capital do Afeganistão. Também é a cidade mais populosa do país.
} 
Em paralelo às postagens sobre o Afeganistão, Curtis publicou histórias sobre o Congo Belga intituladas Kinshasa: city number two ${ }^{9}$. Pela similaridade de nomenclatura e de construção formal destes textos sobre o Congo com aqueles que descrevem Kabul, fica claro que a intenção inicial de Curtis era realizar um único projeto em que as realidades de ambas as cidades seriam apresentadas e comparadas entre si numa proposta crítica aos seus respectivos projetos de colonização e de interferência político-administrativa posterior, suscitada por homens brancos. Contudo, em virtude da quantidade de informações pesquisadas, o que sucedeu de fato foram dois projetos distintos de documentário: a minissérie de 2011, All Watched Over By Machines of Loving Grace, e o longa-metragem de 2015, Bitter Lake.

No caso da série de 2011, a pesquisa feita sobre o Congo é incluída em seu terceiro e último episódio. Nos dois episódios anteriores, Curtis se dedica a analisar a influência da filosofia objetivista da escritora russoamericana Ayn Rand (1905-1982) sobre as visões de mundo compartilhadas por agentes do mercado financeiro estadunidense e por utopistas do setor de tecnologia da informação no estado da Califórnia de fins do século 20, e como isso tudo se deu em paralelo ao desenvolvimento da cibernética enquanto disciplina que viria a organizar uma série de então novos campos do saber - como é o caso da ecologia e da teoria de interpretação sistêmica da natureza, que foi muito popular em seus primórdios. Partindo de bases conceituais propostas originalmente pelo matemático estadunidense Norbert Wiener (1894-1964) ${ }^{10}$ acerca de ciclos contínuos de feedback nos processos de comunicação compartilhados por animais e máquinas, essa teoria comporta uma visão racionalista da natureza e da sua possível acepção na forma de ecossistemas que se autorregulam ao estimularem uns aos outros mutualmente. Segundo Curtis ${ }^{11}$, ecólogos pioneiros tais como os irmãos Howard (1924-2002) e Eugene Odum (1913-2002) ${ }^{12}$ estavam imbuídos de um desejo de ordenação mecanicista do mundo decorrente de pesquisas da época similares às conduzidas por Wiener na área da cibernética, e deixaram de compreender a complexidade da natureza em seu conjunto, passando a enxergá-la de maneira demasiadamente simplificada e apartada da humanidade. Tal postura é relacionada pelo cineasta com o que ocorreu nos domínios belgas na África no início do século 20 , onde a derrocada de poderio do colonizador acompanhou os esforços deste na geração de conflitos entre grupos étnicos que, outrora, conviviam pacificamente. A guerra declarada entre hutus, twas e tutsis em Ruanda veio em decorrência de tal mobilização racista, cujas consequências genocidas se deram numa proporção que atingiu aproximadamente 1 milhão de mortos.

Curtis toma o ocorrido no genocídio em Ruanda como um estudo de caso da interferência colonizadora do Ocidente sobre a soberania de povos diversos que degringola em tragédia justamente porque tal diversidade étnica é achatada perante as imposições tecnológicas, econômicas e políticas do colonizador. No entanto, para Curtis, a maior ironia reside no fato de que o próprio processo de exploração de minerais preciosos para a indústria ocidental de alta tecnologia foi impactado pela chegada de dezenas de milhares de refugiados ruandeses no Congo. Aproveitando-se do caos gerado, milícias a favor e contra o governo local batalharam ferozmente pelo controle das minas.

\footnotetext{
${ }^{9}$ Kinshasa é a capital e a maior cidade da República Democrática do Congo. Foi fundada pelo explorador britânico Henry Morton Stanley (1841-1904) em 1881 como um posto comercial situado às margens do Rio Congo, com o nome Léopoldville, dado em homenagem ao rei Leopoldo II da Bélgica.

${ }^{10}$ WIENER, Norbert. Cybernetics: or Control and Communication in the Animal and the Machine. 2. ed. Cambridge: MIT Press, 2019.

11 CuRTIS, Adam (dir.). All Watched Over by Machines of Loving Grace [Minissérie para TV]. Reino Unido: British Broadcasting Corporation, 2011. color. son. 180 min (3 episódios).

${ }^{12}$ Eugene Odum escreveu o conhecido livro Fundamentos de Ecologia. Originalmente publicado em 1953, trata-se de uma das mais importantes obras inaugurais para a compreensão da natureza enquanto conjunto de ecossistemas interrelacionados (na acepção que temos de ecossistemas nos dias de hoje).
} 
A situação prova ser ainda mais dramática quando se leva em conta que, no auge da crise dos refugiados ruandeses em 1994, a República Democrática do Congo ainda era conhecida como Zaire e era por muito tempo governada pelo ditador Mobutu Sese Seko (1930-1997). Se, logo após a independência do Congo em relação aos belgas em 1960, o país tinha um futuro promissor reservado às causas sociais nas vistas de um governo de alinhamento socialista capitaneado pelo primeiro-ministro Patrice Lumumba (1925-1961), o golpe de Estado que levou Seko ao poder em 1965 com o apoio implícito da Bélgica e dos Estados Unidos frustrou quaisquer expectativas nesse sentido. Registros obtidos dos arquivos da BBC e compartilhados por Curtis em seu blog atestam o que foram esses anos iniciais de democracia no Congo antes dos conflitos armados entre facções políticas e militares rivais se tornarem parte recorrente da rotina congolesa até a queda de Seko.

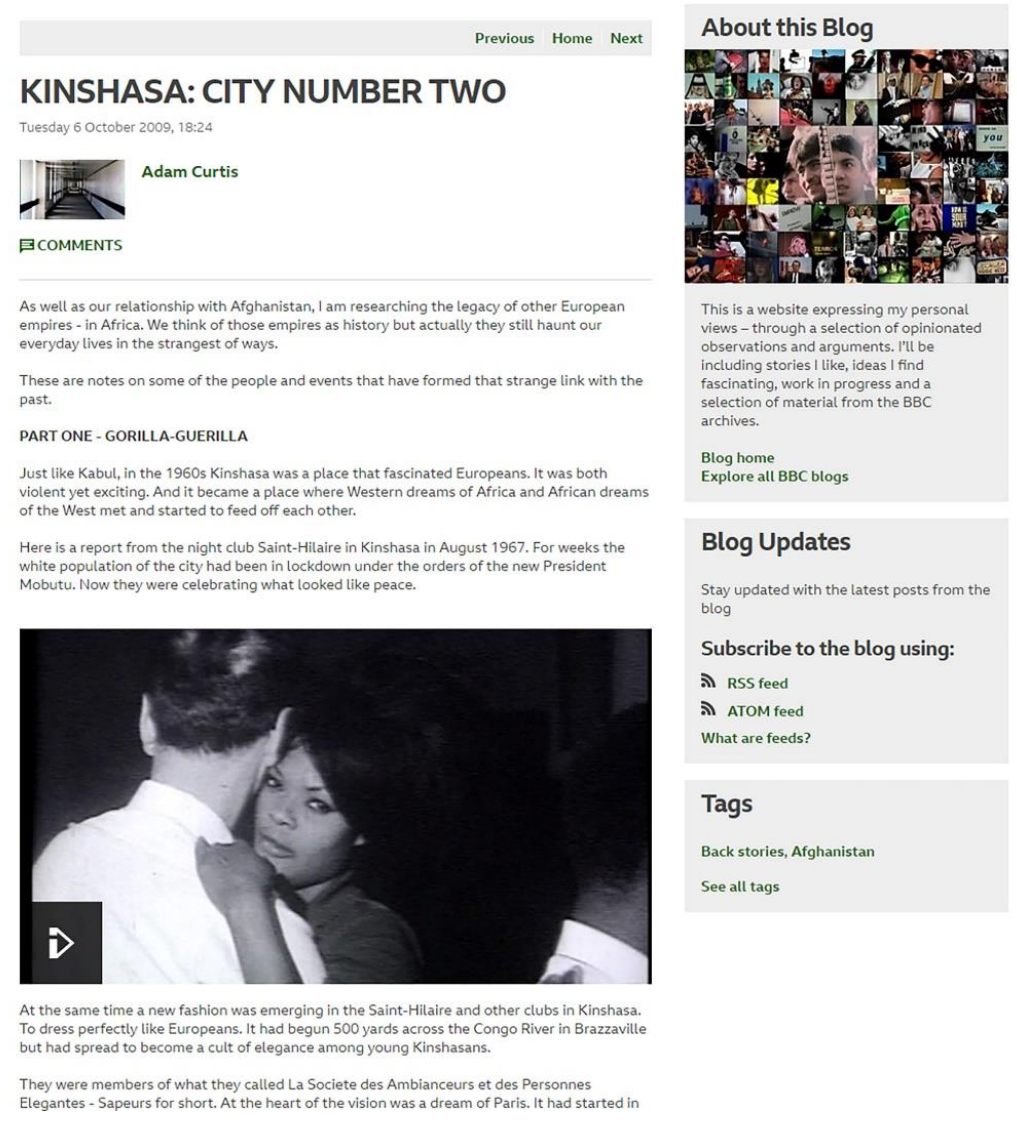

Figura 3: Captura de tela que mostra parte de postagem feita sobre o Congo no blog de Curtis. Fonte: CURTIS, Adam. The Medium and the Message. Disponível em: <https://www.bbc.co.uk/blogs/adamcurtis/entries/ 7759d0f2-a3ca-31f8-96df-6b71524f926e>. Acesso em: 03 jul. 2020.

Além de reapresentar algumas dessas imagens de arquivo, All Watched Over... ainda faz uso esparso de entrevistas com especialistas - porém, em bem menor número que em The Trap. Curtis só viria a abolir totalmente o dispositivo em questão em seu projeto seguinte: Bitter Lake (2015).

Ao invés de adotar o formato de minissérie com o qual costumava trabalhar, o cineasta decidiu editar boa parte do conteúdo pesquisado por ele até então sobre o Afeganistão na forma de um longa-metragem exibido diretamente na televisão pela BBC. Com aproximadamente 2 horas e 15 minutos de duração, Bitter Lake descreve o processo de expurgo de fundamentalistas islâmicos da Arábia Saudita para mesquitas no Paquistão nas quais também se formaram intelectual e ideologicamente os talibãs. Estes viriam a ser recrutados e treinados por 
agentes estadunidenses interessados em reaver investimentos feitos e expulsar os soviéticos do Afeganistão, que vieram a ocupar o país em suporte ao governo que ajudaram a implantar em 1978.

Ao discorrer sobre o histórico de sucessivas ocupações e momentos de instabilidade política no Afeganistão em Bitter Lake, Curtis aproveita a farta quantidade de material não-editado obtido dos arquivos da BBC para problematizar a ética (não) empregada em procedimentos de captura de algumas das imagens utilizadas. É emblemática a cena que Curtis traz de um repórter pedindo para que um homem afegão se aproxime e se relacione de determinado jeito com a própria filha que se recupera de ferimentos graves em um hospital local. Certamente os telespectadores que tiveram acesso a essa reportagem da BBC na época em que ela foi originalmente transmitida (e devidamente editada) só viram um pai afagar carinhosamente a filha ferida. Por mais que houvesse amor verdadeiro entre o adulto e a criança retratados, a situação inteira fora forjada por pessoas estranhas à família. O objetivo era o de provocar um estímulo afetivo específico no espectador: a compaixão. Mas, ironicamente, quem parecia não ter compaixão para com a família ou com sua necessidade de privacidade naquele momento de dor era a equipe de filmagem.

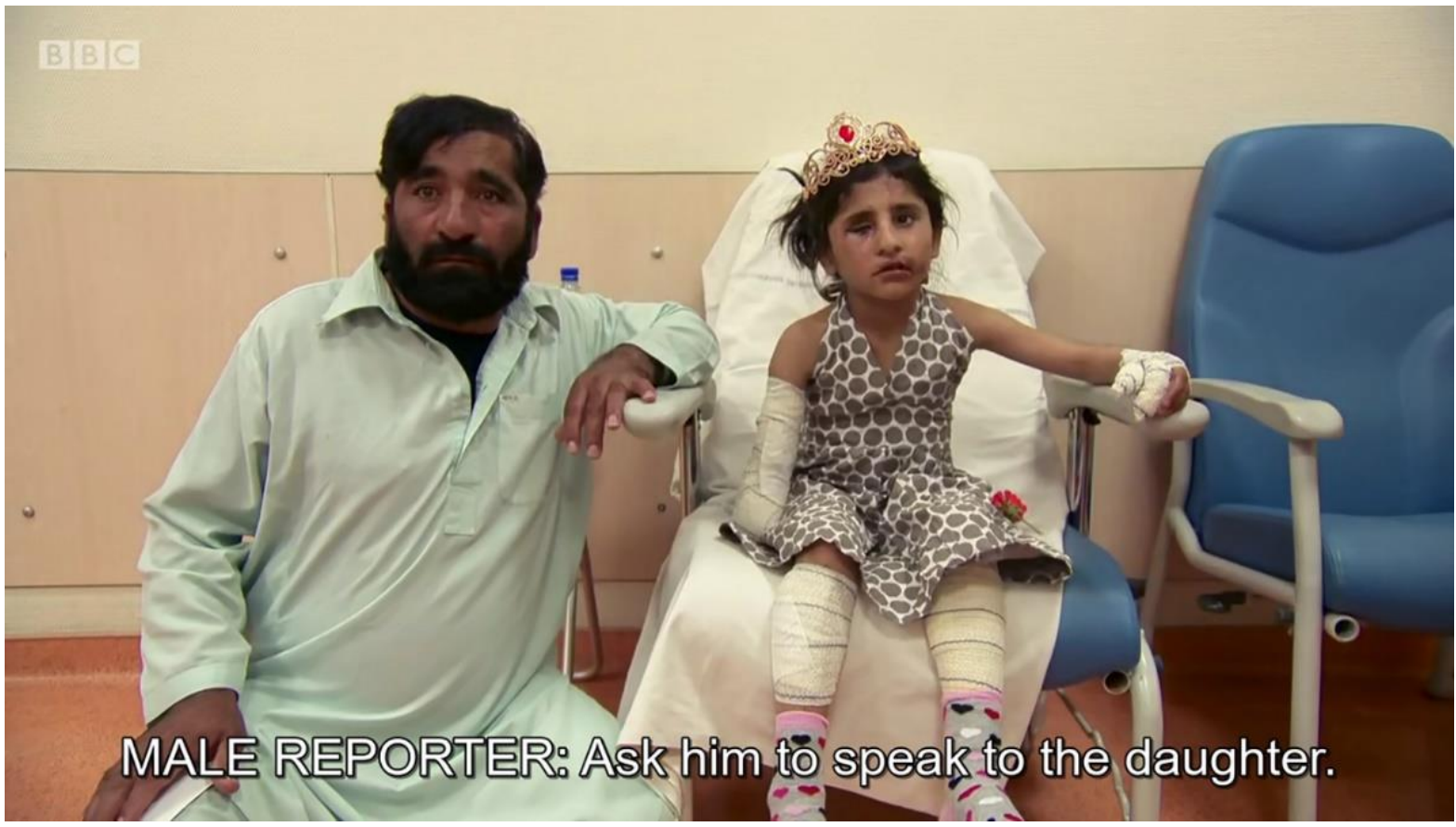

Figura 4: Fotograma de início de vídeo não-editado de reportagem feita pela BBC no Afeganistão em 2001. Fonte:

CURTIS, Adam (dir.). Bitter Lake [Longa-metragem]. Reino Unido: British Broadcasting Corporation, 2015.

Outro interessante dispositivo retórico que Curtis emprega em Bitter Lake é a intercalação de alguns registros de época do Afeganistão com excertos de um filme de comédia britânico de 1968 intitulado Carry On Up The Khyber, no qual as relações entre colonizador e colonizado são ridicularizadas a ponto de se desconectarem totalmente da realidade de incontáveis mortes ocasionadas pelo domínio imperialista britânico sobre povos que habitavam a região atualmente compreendida pelo Paquistão e parte do Afeganistão. Em um flagrante exemplo de whitewashing no referido filme, atores e atrizes brancos interpretam personagens afegãos e indianos de forma caricata ou estereotipada, enquanto que, no outro lado do conflito, soldados britânicos mantêm a ordem colonial (e a certeza de sua masculinidade) não usando cuecas por baixos de seus kilts. 


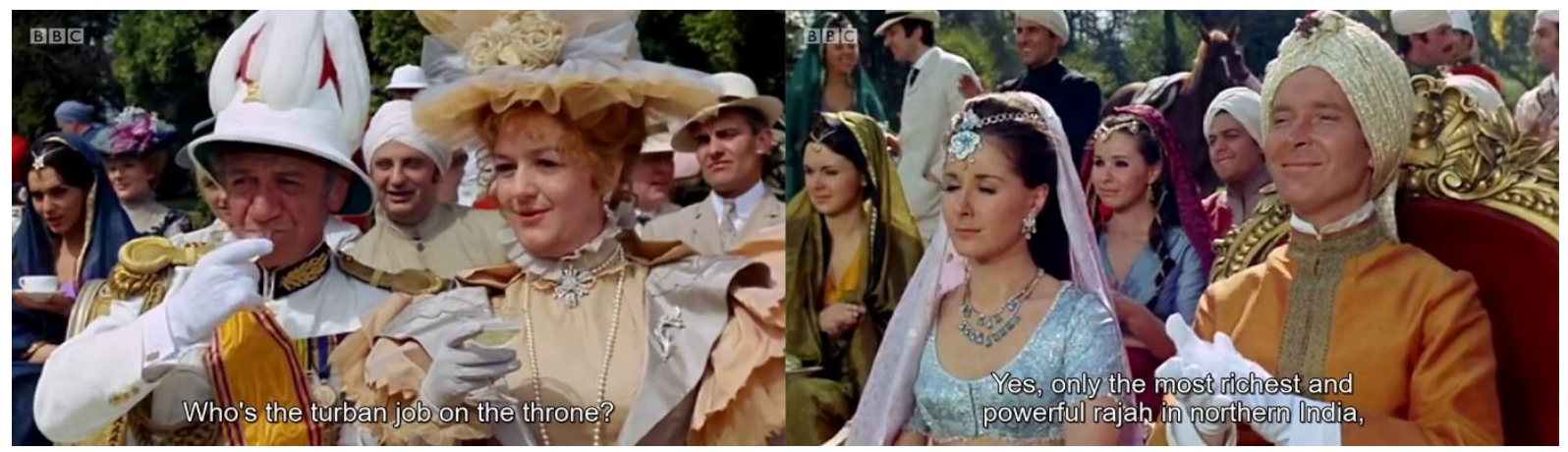

Figura 5: Fotogramas extraídos de uma das cenas de Carry On Up The Khyber (1968) reproduzidas em Bitter Lake, nos quais aparecem o Khasi de Khalabar (interpretado por Kenneth Williams) e sua filha (Angela Douglas). Ambos são atores britânicos brancos interpretando personagens de origem indiana. Fonte: THOMAS apud CURTIS, Adam (dir.). Bitter Lake [Longa-metragem]. Reino Unido: British Broadcasting Corporation, 2015.

Essa consciência crítica de Curtis acerca dos processos de colonização e de sua continuidade na forma de diferentes níveis de colonialidade contemporâneos não evita que ele caia em contradições de vez em quando. A decisão criativa por trás da forma como Bitter Lake foi montado, privilegiando imagens de arquivo captadas por uma empresa da grande mídia europeia, recorreu na falta de espaço oferecido para falas situadas. Tanto que, no decorrer do filme, são raras as vezes em que afegãos falam para a câmera. Quase não se ouve suas vozes, nem suas opiniões próprias, medos, desejos ou expectativas. Parecem ser meros observadores da passagem de agentes estrangeiros pelo seu próprio país. Logo, a experiência que temos do Afeganistão que Curtis mostra em Bitter Lake ainda é aquela mediada por imagens eurocêntricas. Porém, seu blog possibilita uma ampla mirada aos bastidores da produção, o que nos permite supor que o inevitável filtro de conteúdo - aquele que fez 18 terabytes de pesquisa caberem em pouco mais de 2 horas de filme - deixou muita coisa de fora, descartada na ilha de edição.

\section{Outras postagens de interesse}

Por ser uma pessoa identificada com a esquerda política britânica, Curtis utiliza seu blog também como um espaço para compartilhar e comentar criticamente histórias que falam de curiosidades envolvendo a configuração do capitalismo financeiro global tal como é conhecido atualmente. Em grande medida, são histórias desenvolvidas a partir de imagens de arquivo às quais Curtis teve acesso via $\mathrm{BBC}$, mas que não puderam ser relacionadas diretamente com nenhum de seus projetos pessoais até o momento.

Vale destacar algumas delas a seguir. Na postagem datada de novembro de 2009 e intitulada Dubai 1975, Curtis recupera um documentário feito no ano indicado sobre o então príncipe e atual emir de Dubai, o xeique Mohammed bin Rashid Al Maktoum. Trata-se de uma das figuras centrais no processo de inserção dos Emirados Árabes Unidos no comércio internacional de petróleo e na consequente modernização e configuração de Dubai enquanto cidade global, enriquecida à custa de muitos trabalhadores mal remunerados.

Em janeiro de 2010, Curtis faz uma postagem que investiga o processo de formação de células terroristas no Iêmen dos dias de hoje. Explica como o problema remonta a questões históricas decorrentes do imperialismo britânico que foram pouco exploradas pelas narrativas oficiais dos conflitos armados no Oriente Médio desde a Segunda Guerra Mundial.

Em outra postagem de 2010, de março, intitulada Guinea Pigs Up the Creek, Curtis apresenta materiais que pesquisou a respeito dos yanomami e que informam melhor, do ponto de vista da cultura visual, sobre as 
mistificações e idealizações que serviram de ponto de partida para expedições tais como a empreendida por Napoleon Chagnon e Tim Asch, que resultou no filme The Ax Fight.

Em dezembro de 2010, dado o ocorrido com Chelsea Manning após o escândalo da denúncia de Edward Snowden sobre o sistema de monitoramento global gerenciado pela National Security Agency (NSA), Curtis relembra alguns casos de whistleblowers (informantes) do passado, envolvidos com as negociações para a entrada dos Estados Unidos na Segunda Guerra Mundial antes de Pearl Harbour.

Enfim, muitas dessas e outras postagens - que também foram feitas com mais frequência por Curtis até 2012 - podem ser localizadas na seção tags do blog, identificadas como back stories (histórias de fundo) ${ }^{13}$. São textos redigidos pelo cineasta quase em forma de causos, empregando frases curtas, julgamentos de valor irrestritos, pouco jargão técnico e um estilo de linguagem que, por mais que não seja coloquial, coloca o leitor numa condição próxima a de um confidente. Nessas back stories, Curtis parece convidar o internauta a puxar uma cadeira e ouvir atentamente o que ele tem a dizer a respeito do capitalismo, do colonialismo, do terrorismo, da xenofobia, da sociedade informatizada e de todas suas interseccionalidades e complexificações, impossíveis de serem discutidas com profundidade em um ou mais projetos de documentário realizáveis dentro do período de tempo abarcado por uma só vida humana.

\section{Redes de criação e criação em rede}

Uma vez que é possível compreender processos de criação artística como redes de pensamento e de práxis interconectadas ${ }^{14}$, nas quais o intelecto, os afetos, a memória e as experiências de vida de um dado criador se cruzam para conduzi-lo à feitura de novas obras, cabe dizer que blogs, redes sociais e outros recursos de compartilhamento de saberes, de técnicas e de visões de mundo na Internet podem constituir aquilo que o teórico francês Pierre Lévy denomina como novas tecnologias da inteligência ${ }^{15}$. Não obstante, são tecnologias como essas que permitem desmistificar processos criativos no geral. Longe de ser produto da inspiração divina ou da pura espontaneidade, uma peça audiovisual demanda um extensivo trabalho de pesquisa em sua etapa de pré-produção. Obtém-se conteúdo de todo tipo em tal procedimento: textos, imagens, sons, vídeos e outros recursos multimídia que enriquecem o entendimento do artista em relação àquilo que parece lhe escapar nos instantes em que sua ideia ainda se apresenta como algo embrionário. Nesse sentido, é complementando e indo além das limitações formais de livros ou de outras "velhas" tecnologias de inteligência que a própria natureza hipertextual do blog permite articular essa variedade de conteúdo e apresentá-lo de forma coerente, em uma mesma plataforma facilmente acessível por um dado internauta em qualquer lugar do planeta.

Em blogs tais como o de Adam Curtis, nota-se uma transição da ideia original de redes de criação para um modo de pensar mais em termos de criação em rede. Afinal, são metodologias de compartilhamento de processos criativos como essas que convidam o já referido internauta a registrar sua opinião e a participar minimamente de seu desenvolvimento ou divulgação. Assim sendo - pelo menos em teoria -, estabelece-se um canal de comunicação direta com o artista, a quem ainda cabe a decisão final de responder a críticas, sugestões ou elogios feitos pelas pessoas que acompanham seu trabalho. Mas como a participação delas pode ser efetivamente mensurada? Em que medida a visão do autor da obra ou da instituição que lhe dá respaldo se sobrepõem a tais

\footnotetext{
${ }^{13}$ Vide: https://www.bbc.co.uk/blogs/adamcurtis/tags/back-stories. Acesso em 03 jul. 2020.

${ }^{14}$ SALLES, Cecília A. Redes da criação: construção da obra de arte. Vinhedo: Horizonte, 2006. p. 17.

${ }^{15}$ LEVY, Pierre. As tecnologias da inteligência: o futuro do pensamento na era da informática. 2. ed. São Paulo: Editora 34, 2010, p. 15.
} 
vontades e expectativas? Os meios (a TV, a internet, o blog) podem ainda determinar a mensagem que o autor deseja transmitir? E como isso se dá numa perspectiva instituição-autor versus público-autor?

No que diz respeito ao público - ou aos internautas, para ser mais preciso - é difícil responder a todos esses questionamentos no âmbito deste artigo, já que o envolvimento mais ativo de Curtis com seu blog antecedeu em pouco a intensificação do fenômeno contemporâneo das shitstorms nas redes sociais ${ }^{16}$ - ondas efêmeras, instantâneas e coletivas de revolta direcionadas contra a integridade moral de uma dada pessoa, empresa, governo ou organização. Fãs revoltados com alguma decisão criativa polêmica dificilmente atingiriam Curtis com comentários maldosos ou com tentativas de "cancelamento", uma vez que, em 2014, ele já havia deixado de fazer postagens com regularidade. Sua última publicação no blog data de 2016. É a única feita pelo cineasta naquele ano, servindo somente como anúncio de lançamento de seu projeto de documentário mais recente via BBC: HyperNormalisation.

Dada a atual condição de aparente abandono do blog, é válido assumir que Curtis não lê mais os comentários salvos na plataforma. A maioria deles data do período de auge das postagens de Curtis (2009 a 2012), e são elogiosos em sua maioria. No entanto, o que chama a atenção é que, menos do que dialogar diretamente com Curtis, o que a área de comentários do blog fomentou foi um diálogo entre seus seguidores. Especialmente em 2009 - o primeiro ano de existência do blog -, internautas trocaram entre si referências complementares àquelas mencionadas por Curtis nas postagens das séries Kabul... e Kinshasa.... Os comentários se tornaram um fórum online para entusiastas do trabalho de Curtis. Esses debateram não só aspectos abertamente associados às obras, mas questões envolvendo o alinhamento político-ideológico de Curtis (e como isso orienta a retórica de seus documentários, por consequência), os parâmetros de copyright de boa parte do conteúdo compartilhado no blog, entre outras.

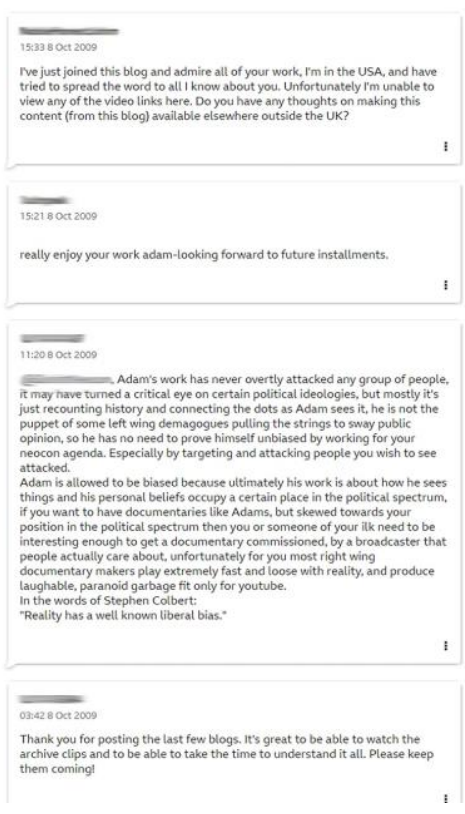

Figura 6: Captura de tela que mostra alguns dos comentários feitos por internautas a uma das postagens do blog sobre o Congo. Fonte: CURTIS, Adam. The Medium and the Message. Disponível em: <https://www.bbc.co.uk/ blogs/adamcurtis/entries/7759d0f2-a3ca-31f8-96df-6b71524f926e\#comments>. Acesso em: 03 jul. 2020.

\footnotetext{
${ }^{16}$ PereIRA, Luiz I.; CALDAS, Camilo O. L. O fenômeno Shitstorm: Internet, intolerância e violação de direitos humanos. Interfaces Científicas, $\quad$ v. $\quad 6, \quad$ n. $\quad 1, \quad 2017, \quad$ p. $123-134$. Disponível em: https://periodicos.set.edu.br/index.php/humanas/article/view/3540. Acesso em: 03 jul. 2020.
} 
Certamente, a restrição de acesso a determinados conteúdos disponibilizados no blog a endereços IP localizados exclusivamente no Reino Unido não se trata de uma decisão de Curtis. Trata-se de uma orientação vinda da própria $\mathrm{BBC}$ em consideração às leis de proteção de direito autoral em vigência no país. Mas vale reforçar que o blog em si é hospedado em um domínio gerido pela BBC. Logo, não seria estranho constatar que toda informação publicada ali passe por alguma espécie de crivo institucional, por menor que seja essa interferência. $\mathrm{O}$ mesmo pode ser dito a respeito dos filmes de Curtis, já que estes são, em sua maioria, projetos comissionados pelo canal. Apesar de reafirmarem constantemente a forma particular do cineasta de se expressar, são filmes que dependem cada vez mais dos arquivos da BBC para serem concretizados. Curtis ainda detém o controle criativo e a decisão a respeito do corte final dos referidos projetos, claro, mas percebe-se em seus posicionamentos uma cautela que implica em não propor temas que afrontem diretamente pontos de vista defendidos por seus patronos. Pode não haver tanto uma formatação explícita, mas há pelo menos uma modulação de informações em jogo: a mensagem de Curtis é influenciada pelo meio em que é veiculada. Seja este meio o blog ou o canal de TV em que seus filmes são exibidos inicialmente, a BBC está presente de forma incontornável no processo criativo de Curtis. Há uma cadeia de decisões que envolve diferentes profissionais (diretores de programação, produtores, agentes de relações públicas, desenvolvedores web, etc.) à qual Curtis está sujeito, querendo ou não. O meio e a mensagem tornam-se novamente indistinguíveis um do outro, tal como McLuhan sugeriu.

\section{Considerações finais}

Reconhece-se que a estrutura que organiza as informações tornadas públicas através do blog de Curtis reflete a estrutura de seus projetos mais recentes. Tanto o blog em si quanto documentários como Bitter Lake ou HyperNormalisation empregam a mecânica do banco de dados herdada do meio informacional digital para apresentar suas respectivas informações sem um compromisso direto com a linearidade temporal. A narrativa é fragmentada, o que permite tanto ao telespectador quanto ao internauta acessar a pesquisa de Curtis a qualquer momento e conectar os pontos por si só, de acordo com seu interesse maior em um ou outro assunto discutido dentro das temáticas macro exploradas pelo cineasta. Em Bitter Lake, por exemplo, nota-se uma cronologia de fatos apresentados, mas ela não é pré-requisito para se obter um certo entendimento acerca de quanto o Afeganistão sofreu na gangorra geopolítica tensionada entre EUA e União Soviética no período da Guerra Fria. Ou ainda, em HyperNormalisation, tal cronologia não impede que o documentário seja visto pela primeira vez a partir de qualquer ponto, ou revisitado vezes depois para informar sobre as possíveis conexões entre a política internacional simplificadora de Ronald Reagan para com o Oriente Médio de fins dos anos 1980 e o crescimento de milícias fundamentalistas na região tais como o Estado Islâmico.

De todo modo, vale ressaltar que Curtis se apropria sabiamente da tessitura hipertextual da Internet para criar documentários nos quais se vê que a independência de uso de recursos do léxico documental clássico não é completa. Ainda respondem a um aporte institucional que demanda o uso de uma voz-de-Deus masculina do saber e de uma perspectiva branca e eurocentrada, por exemplo. Contudo, são projetos em que se admitem respiros - ou seja, espaços de tempo em que o telespectador/internauta pode refletir consigo mesmo ou com seus pares para tirar conclusões particulares daquilo que vê. A duração prolongada de imagens de arquivo reproduzidas de forma não-editada por Curtis pode ser indigesta para muitos, mas é um incentivo para outro tipo de independência valiosa: a emancipação intelectual do espectador.

Sabe-se que a essência das notas de rodapé é por si só hipertextual, e que é possível compreender as postagens do blog de Curtis como tais, já que nos apresentam diversos aspectos interconectados e complementares para a compreensão do conjunto da obra do cineasta. Além disso, essas postagens nos oferecem 
uma perspectiva aprofundada e ampla do modo como Curtis reconhece o mundo, e de como o mundo o reconhece em contrapartida. O conteúdo disponibilizado em seu blog permite identificar motivações para a realização de cada um de seus filmes, e convida o espectador que os assiste pela primeira vez a procurar saber mais sobre quem é Curtis e o que ele pensa a respeito da tecnopolítica contemporânea.

Finalmente, pelo fato de estar há anos sem atualizações, é preciso admitir que o blog não oferece quaisquer pistas acerca dos projetos futuros de Curtis. Mas há expectativas, e é preciso também considerar que, uma vez que se propôs a trabalhar exclusivamente com imagens de arquivos, Curtis precisa lidar com material gravado previamente por pessoas com uma visão não tão desconstruída do Outro quanto a dele. Nesse sentido, sua experiência profissional como um todo não pode ser desprezada, mas se Curtis vem optando por descolonizar sua perspectiva crítica, esperamos que busque fazê-lo para além da superficialidade das imagens na ilha de edição, e a favor dos sons - das vozes dos indivíduos sub-representados em seus e em tantos outros filmes. Mencioná-los em notas de rodapé, mesmo que elaboradas como textos muito bem escritos e extensos em um site da internet mundialmente acessível, não basta. A cultura visual ocidental como um todo já invisibilizou disputas da diferença por tempo demais.

\section{Referências bibliográficas}

BOURRIAUd, Nicolas. Pós-produção: como a arte reprograma o mundo contemporâneo. São Paulo: Martins Fontes, 2009.

Chagnon, Napoleon; Asch, Tim. The Ax Fight [Curta-metragem]. Estados Unidos: Documentary Educational Resources, 1975. color. son. 30 min.

CuRTIS, Adam (dir.). All Watched Over by Machines of Loving Grace [Minissérie para TV]. Reino Unido: British Broadcasting Corporation, 2011. color. son. 180 min (3 episódios).

(dir.). Bitter Lake [Longa-metragem]. Reino Unido: British Broadcasting Corporation, 2015. color. son. $136 \mathrm{~min}$.

(dir.). HyperNormalisation [Longa-metragem]. Reino Unido: British Broadcasting Corporation, 2016. color. son. $166 \mathrm{~min}$.

The Medium and the Message (Adam Curtis's blog). Disponível em: http://www.bbc.co.uk/blogs/adamcurtis. Acesso em: 03 jul. 2020.

(dir.). The Trap: What Happened to Our Dream of Freedom? [Minissérie para TV]. Reino Unido: British Broadcasting Corporation, 2007. color. son. 180 min (3 episódios).

LEVY, Pierre. As tecnologias da inteligência: o futuro do pensamento na era da informática. 2. ed. São Paulo: Editora 34, 2010.

MANOVICH, Lev. The language of new media. Cambridge: MIT Press, 2001.

MCLUHAN, Marshall. Os meios de comunicação como extensões do homem. 6. ed. São Paulo: Cultrix, 1988.

NiCHOLS, Bill. Introdução ao documentário. 5. ed. Campinas: Papirus, 2005.

ODUM, Eugene P. Fundamentos de ecologia. 7. ed. Lisboa: Fundação Calouste Gulbenkian, 2004.

PEREIRA, Luiz I.; CALDAS, Camilo O. L. O fenômeno Shitstorm: Internet, intolerância e violação de direitos humanos. Interfaces Científicas, v. 6, n. 1, 2017, p. 123-134. Disponível em: https://periodicos.set.edu.br/index.php/humanas/article/view/3540. Acesso em: 03 jul. 2020.

SALLES, Cecília A. Redes da criação: construção da obra de arte. Vinhedo: Horizonte, 2006.

ThomAs, Gerald (dir.). Carry On Up The Khyber [Longa-metragem]. Reino Unido: The Rank Organisation / Peter Rogers Productions. color. son. $88 \mathrm{~min}$. 
WIENER, Norbert. Cybernetics: or Control and Communication in the Animal and the Machine. 2. ed. Cambridge: MIT Press, 2019.

WINNER, Langdon. Do artifacts have politics? In: The Whale and the Reactor. a search for limits in an age of high technology. Chicago: The University of Chicago Press, 1986, p. 19-39.

Recebido em: 24 de janeiro de 2020 Aceito em: 03 de julho de 2020 